\title{
Evaluation Research on the Innovation Efficiency as Value-chain Framework: Evidence from Jiangsu Province
}

\author{
Xuezhen Zhu \\ Department of Accounting, Dongwu Business School, Soochow University \\ Suzhou, 215000, China \\ Email: zhuxuezhen@suda.edu.cn
}

Keywords: Network DEA model; R\&D efficiency; technological commercialization efficiency; overall innovation efficiency

\begin{abstract}
Based on the value-chain framework, the innovation system was divided into two interactive sub-phases: upstream research and development process and downstream technological commercialization process. By introducing network DEA model, we computed the R\&D, the technological commercialization and overall innovation efficiencies for 13 cities of Jiangsu province. The findings were presented as follows. From general prospective, none of innovation R\&D efficiency, technological commercialization efficiency or overall innovation efficiency was high. From the trend prospective, recent years the trend of Jiangsu's innovation efficiency and economic cycle showed synchronicity. From the value chain prospective, upstream R\&D efficiency did not show relation with downstream technological commercialization efficiency, and showed obvious inconsistencies, and the technological commercialization efficiency played a more important contribution to overall innovation efficiency than R\&D efficiency. From the innovation regional prospective, the overall innovation efficiency showed obvious regional distinction, southern Jiangsu ranked first, followed by central Jiangsu and northern Jiangsu. This was the same with the level of economic development.
\end{abstract}

\section{Introduction}

After Shenzhen became the first national experimental innovation-oriented city in 2008, at the beginning of 2010, Dalian, Qingdao, Xiamen, Shenyang, Xi'an, Guangzhou, Chengdu, Nanjing, Hangzhou, Jinan, Hefei, Zhengzhou, Changsha, Suzhou, Wuxi and Yantai were also named as national experimental innovation-oriented city by the National Development and Reform Committee. Innovation had become the main rhythm of economic growth, and had got high attention from the government and companies. Meantime, with the growth of innovative input, optimization of the innovative environment, the construction of innovative terrace and the procession of innovative policy, whether or not the production would grow and the regional difference of innovation efficiency became the focus. How to assess innovation efficiency in order to allocate innovative resource wisely became the key to create innovative city.

Traditional Data Envelopment Analysis (DEA) method evaluated innovation efficiency by viewing the innovation system as a "black box", ignoring the practical efficiency of internal technological commercialization process, and calculated the whole system's innovation efficiency. This thesis evaluates cities' innovation efficiency from value-chain's prospective, dividing innovation process into two inter-related innovation sub-phases: upstream research and development process and technological commercialization process. Using process as guidance, it differentiated technique and market, which were the two factors affecting innovation rate. It evaluates stage efficiency of innovation system along value-chain's upgrading direction, in order to disclose the inefficient parts in the innovation system. By considering the process of innovation and emphasizing the technological commercialization part of innovation, it accelerates the promotion of value chain and pushes the up-shifting of the whole value curve.

\section{Literature Review}

Innovation value-chain is a functional linking mode that uses college and universities, research institutes, companies, governments, intermediary organizations and investment institutions as innovation subjects from finding innovation knowledge to develop innovation technology and finally to realize innovation industrialization and technological commercialization. During this processes, innovation knowledge and technology move along the innovation value-chain, realize innovation value and push the upgrade of value-chain.

Researches of innovation value: From Jian Cai's (2009) view, industrial technology innovation value-chain is a functional linking processes such as demand analysis, technology analysis and estimation, innovation identification, basic research, applied research, design and development, 
manufacturing and technological commercialization [1]. By analyzing $\mathrm{E}$ century equipment manufacturing enterprises' value-chain system, Yujin Wang(2010) succeeded in innovating equipment manufacturing enterprise through managing mode, optimizing $\mathrm{E}$ century equipment manufacturing enterprises' upstream value chain, enterprise production process value-chain and downstream value-chain, creating a more efficient model of source allocation and integration, resulting in efficient use of resource and improvement of equipment manufacturing enterprises' international competitiveness[2].

Researches of innovation efficiency: Using DEA method, Junhong Bai (2009) evaluated the innovation efficiency of regional innovation system. The result showed that China's regional innovation efficiency was rather low, and in all showed decreasing returns to scales, technology resource input was excessive rather than insufficient. Technology efficiency did not show obvious difference within regions, while scale efficiency differed obviously among different regions [3]. Using the revised DEA model, building the technology resource input and output evaluation index based on correlation analysis method, Yan Guan (2011) evaluated Jiangsu province's technology resource allocation efficiency from 2003 to 2007. The result showed that technology resource allocation in most cities in Jiangsu province was inefficient. She analyzed the reason of inefficiency and gave corresponding suggestions [4]. Using DEA method, Qiang Zhu (2009) evaluated the knowledge economy efficiency of each province in China, and estimated the optimal input-output production function [5]. Using two-stage DEA model, Jiancheng Guan and Yin He (2005) divided regional innovation action into technology output stage and economic output stage. He evaluated technology effectiveness, economy effectiveness and overall effectiveness in innovation action, and divided each area into different gradients according to effectiveness value [6]. Based on value-chain view, Yongze Yu (2009) divided the technology innovation process of high-tech industry into two stages: technology development and technology achievement transformation. Also, he used DEA model with slack variables to do empirical research on each stage's efficiency and effecting factors. Results showed that average technology innovation efficiencies in both stages were rather low. Operation degree, enterprise scale government supporting policy and company performance all had positive effect on regional high tech-industry's technology innovation efficiency [7]. By dividing regional innovation activity into two related innovation chain sub-process, Sui Li (2011) evaluated Jiangsu province and other 5 countries and regions overall efficiency of innovation activity and efficiency of every sub-process, based on chain relational network DEA model on variable return to scale. On this basis, he calculated the correlation coefficients of two sub-processes in order to evaluate the degree of associated effectiveness of every regional technology innovation sub-process [8].

From the above papers we can see that, while evaluating innovation efficiency based on traditional DEA model [3][4][5], viewing innovation system as a whole and processing it as "black box", would ignore the internal structure and mechanism of regional innovation system. Although new researches built two processes DEA model [6][7][8], dividing innovation activity into two processes, using the first process output and middle output as the input of second process, in order to evaluate the overall efficiency and every process efficiency of innovation system, considering the actual input and output of each process from the view of value chain.

Recent years, with the innovation of DEA model, innovation process was divided into two phases: technology development as the upstream and technology commercialization as the downstream of value chain. Beside the consideration of middle input's connecting function, which was the relationship between the upstream and downstream of the value chain, it also considered the real input and output of each phase. Using DEA model, Guan (2010-2012) divided innovation process into two sub-phases: technology development as the upstream and technology commercialization as the downstream of value chain and evaluated the high-tech industry system [9] and regional innovation system of each province in China [10] and innovation system efficiency of 20 OECD countries [11]. The results showed that upstream technology development and downstream technology commercialization were inconsistent, technology commercialization had great effect on innovation performance.

\section{Innovation Efficiency Model Design}

A. Network DEA innovation efficiency evaluation model based on value chain

According to Chen's (2004) [12], Chiu's (2010, 2011) [13,14], and Guan's (2012) [15] network DEA model, we divided innovation activity into development phase and economic transformation phase. Referring to Zhong's (2011) [15], Li's (2011) [16] and Guan's (2012) [11] choice of Regional innovation efficiency index system, we create DEA innovation efficiency model based on value chain (figure 1). The inputs of first process are R\&D cost, technology funding and 
R\&D employees; outputs are patent application and patent authorization. The inputs of second process are patent application, patent authorization, technology employees, company's total assets and the number of employees at the end of the year; outputs are high-tech output value and per capita GDP.

\section{B. Sample selection and index selection}

(1)Sample selection and data resources

Sample comes from 13 cities in Jiangsu province and is divided into three regions: southern Jiangsu, middle Jiangsu and northern Jiangsu. Southern Jiangsu includes Nanjing, Wuxi, Changzhou, Suzhou and Zhenjiang. Middle Jiangsu includes Nantong, Yangzhou and Taizhou. Northern Jiangsu includes Xuzhou, Lianyungang, Huai'an, Yancheng and Suqian.

Sample data come from panel data of 13 cities in Jiangsu province. Date resources come from Jiangsu Technology Yearbook, Jiangsu Data Yearbook and intellectual property year report. Considering the time lag of innovation output relative to innovation input, we used regression analysis and considered the methods used by most research papers, setting time lag as two years and the time lag of innovation R\&D process and technological commercialization process one year for each.

(2)Innovation efficiency index system

This thesis uses the R\&D to GDP ratio (x1), government science and technology expense to public expenditure ratio (x2), R\&D employees to all employees ratio (x3) as innovation $R \& D$ process input index, and uses the amount of patent application (z1) and the amount of patent authorization (z2) as the data of innovation first process output.

This thesis uses amount of patent application (z1) and the amount of patent authorization (z2) as technology input, total assets of industrial enterprises (z3) as capital input (unit: $¥ 100,000,000$ ), total employees of year end(z4) as employee input (unit:10,000). These four factors are the input of first process. Innovation output uses high-tech production value (y1) (unit: $¥ 100,000,000$ ) and GDP per person(y2) as index.

\section{Empirical Result Analysis}

From overall innovation efficiency of each city in Jiangsu province (table 1 and figure 2), we could see that in first process average R\&D efficiency was 0.486, the second process average technological commercialization efficiency was 0.768 , the average overall innovation efficiency was 0.629. All efficiency ratios showed that none of them was high and the tendency of them matched economic cycle. From the relation of R\&D efficiency and technological commercialization efficiency, it showed that downstream technological commercialization efficiency was higher than upstream R\&D efficiency and there was no relationship and obvious inconsistencies within them. The technological commercialization efficiency played a more important contribution to overall innovation efficiency than R\&D efficiency. This may be because that most cities in Jiangsu province are in initial stage of innovation, even though they take more innovation resources into R\&D process, and still less innovation successes. On the other hand, the government focused on developing comprehensive cooperation and promoting the transformation from patent products to economy and social benefits, this led to low R\&D efficiency and high technological commercialization efficiency. The non-existence relation between the two stage efficiency revealed that the factors of R\&D efficiency and technological commercialization efficiency were different.

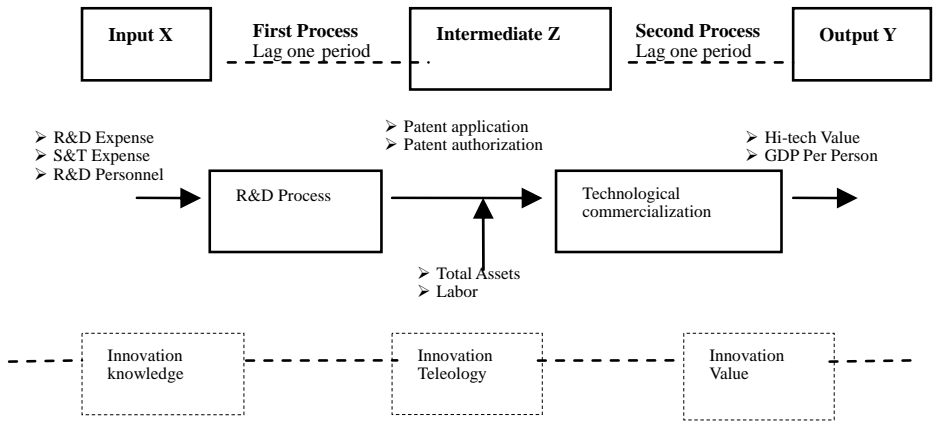

Fig 1 The network DEA model of innovation efficiency

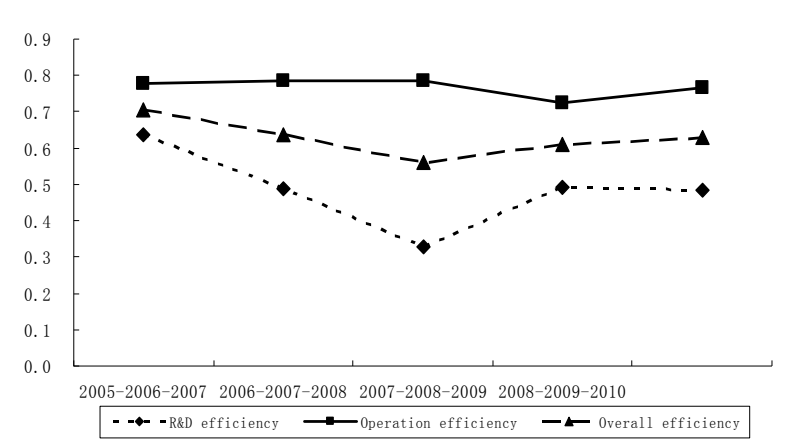

Fig 2 The tendency of mean innovation efficiency in Jiangsu

\section{Conclusion}

Seeing from the region of each city in Jiangsu province (chart 2), R\&D efficiency or technological commercialization efficiency or overall innovation efficiency, the average value of 
Southern Jiangsu was higher than that of middle Jiangsu and middle Jiangsu higher than Northern. This coincided with Jiangsu's regional economy development level. The main cause was that Sothern Jiangsu had abundant innovation resource and the level of commercialization was rather high, so overall efficiency was high.

This thesis uses value chain's angle, and the production of innovation knowledge, the invention of innovation technology and realization of innovation value as process orientation, divides innovation process into two procedures: innovation development and innovation economic transformation. It used innovation data from 3 districts of 13 cities in Jiangsu province from 2005 to 2010. Using network DEA model, we calculated the innovation R\&D efficiency, technological commercialization efficiency and overall innovation efficiency of each city in Jiangsu province, and the following was the results:

From general respective, none of innovation $R \& D$ efficiency, technological commercialization efficiency or overall innovation efficiency was high. This might be that they focused more on R\&D input and commercialization and less on the quantity and quality of output. From the trend prospective, recent years the trend of Jiangsu's innovation efficiency and economic cycle showed synchronicity. This showed that the level of economic, the degree of commercialization, the extent of government's support and the level of enterprise innovation would affect the efficiency of innovation. From the value chain prospective, upstream R\&D efficiency did not show relation with downstream technological commercialization efficiency, and showed obvious inconsistencies, and the technological commercialization efficiency played a more important contribution to overall innovation efficiency than R\&D efficiency. This demonstrated that the innovation efficiencies of different process would have different influence factors. From the innovation regional prospective, the overall innovation efficiency showed obvious regional distinction, southern Jiangsu rank first, followed by central Jiangsu and northern Jiangsu. This was the same with the level of economic development.

\section{References}

[1] Jian Cai. Analysis on the Industry Innovation Chain Intension and the Value Realization Mechanism. Techno economics \& Management Research [J].2009(06):53-55.

[2] Yujing Wang, Wei Chen. The business management innovation model of equipment manufactures based on optimizing value chain. Science and Technology Management Research. [J].2010(01): 127-129.

[3] Junhong Bai, Kesheng Jiang, Jing Li. Research on the Innovating Efficiency of Regional Innovation Systems of China. Management Review [J].2009, 21(09):3-9.

[4] Yan guan, Hecheng Wu, Shun Huang. The efficiency of science and technology resource allocation in Jiangsu Province based on an improved DEA model. Science Research Management [J].2011, 32(02): 145-149.

[5] Qiang Zhu, Yingheng Zhou, Jin Fan. Research on regional Comparison of knowledge economy efficiency. Shanghai Journal of Economics [J].2009(05):22-30.

[6] Jiancheng Guan, Ying He. The performance of Chinese regional innovation system evaluation based on data envelopment analysis. Studies in Science of Science [J].2005, 23(02):265-272.

[7] Yongze Yu. Research on the innovation efficiency of high-tech industrial and its influence factors — based on value chain two stage analyses. Economic Science [J].2009(04):62-74.

[8] Sui Li, Kesheng Jiang, Bingyun Zheng. Evaluation Research on the Regional Innovation Efficiency Based on Chain Relational Network DEA Model: Evidence from Jiangsu Province. Science of Science and Management of S. \& T. [J].2011, 32(11):131-137.

[9] Jiancheng Guan, Kaihua Chen. Measuring the innovation production process: A cross-region empirical study of China’s high-tech innovations. Technovation [J].2010, (30):348-358.

[10] Kaihua Chen, Jiancheng Guan. Measuring the Efficiency of China's Regional Innovation Systems: An Application of Network DEA. Regional Studies [J].2012, 3(46):355-377.

[11] Jiancheng Guan, Kaihua Chen. Modeling the relative efficiency of national innovation systems. Research Policy [J].2012, (41):102-115.

[12] Yao Chen, Joe Zhu. Measuring information technology's indirect impact on firm performance. Information Technology and Management [J], 2004, 5(01):9-22.

[13] Yung-ho Chiu, Chin-wei Huang, Yu-Chuan Chen. The R\&D value-chain efficiency measurement for high-tech industries in china. Asia-pacific Journal of operational Research [J].2010, 63(06):118-135.

[14] Yung-ho Chiu, Chin-wei Huang, Chun-Mei Ma . Assessment of China transit and economic efficiencies in a modified value-chains DEA model. European Journal of Operational Research [J].2011, 209 (02):95-103. 